\title{
Beauty, sanctity and development
}

\author{
Kantha Lankathileke \\ Department of Community Medicine, Faculty of Medicine, University of Colombo, Sri Lanka \\ Correspondence: kantha@ commed.cmb.ac.lk
}

DOI: https://doi.org/10.4038/jccpsl.v24i4.8193

Received on: 1 December 2018

Accepted on: 14 December 2018

The cover picture depicts a panoramic view of Kandy City on a misty morning, captured from the top of mountain Bahiravokanda in Sri Lanka. Kandy City is set on a plateau at an altitude of $465 \mathrm{~m}$ above the sea level surrounded by sweeping green mountains which are home to tea estates and biodiverse rainforests, and nestling amidst low hills, thus called the 'land of the mountains' (1).

Kandy is the country's religious and cultural centre and has been declared by UNESCO as a World Heritage site since 1988 (2). Originally known as 'Senkadagalapura', Kandy City has been named after a Brahmin named 'Senkada' who lived in a cave near the city. It was the last kingdom of Sinhalese rulers and retains its grandeur and elegance to date. It is still the home of arts and crafts, music and dance which flourished under the patronage of the Kandyan Kings. The iconic landmark of Kandy City is 'Dalada Maligawa', also known as 'temple of the sacred tooth relic of Lord Buddha' (not captured

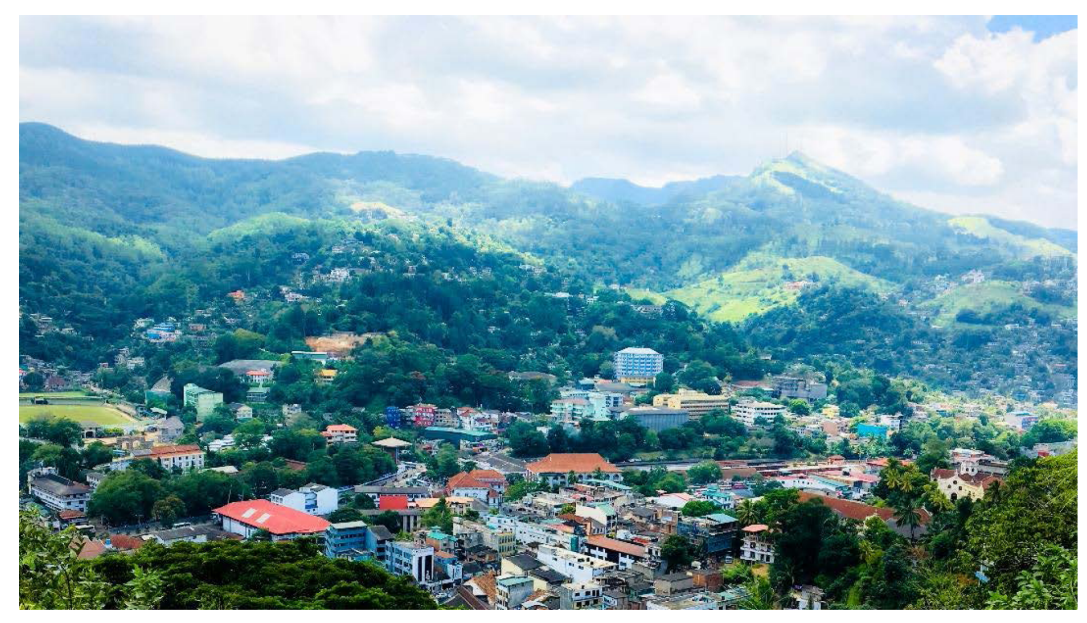
from Bahiravokanda direction). The annual event of Dalada Maligawa is the colourful pageant with exotically costumed drummers, dancers and about 80-100 caparisoned elephants during the month of August, making the Kandy City nights glitter. The magnificent casket placed on the Temple Tusker contains the sacred tooth relic.

At present, Kandy stands as the second largest city of Sri Lanka. Its population has grown rapidly over the years and currently is around 120,000. The picturesque views are obstructed by the ever-increasing unplanned urbanization that had taken place in the city, as shown in the picture due to indiscriminate construction of new buildings within the old city. To the left of this picture is the mountain terrain, some of which is cleared of its vegetation for human settlements. Further, its geographical location has made it a major transportation hub with around 320,000 passenger movements daily on business and on pilgrimage to pay homage to Dalada Maligawa (3). Kandy City is about $26 \mathrm{~km}^{2}$ in area and the daily vehicles that move in and out of the city is about 100,000 (3). This has led to heavy traffic congestion resulting in the air being polluted with fumes released by the heavy flow 
of vehicular traffic. Since Kandy City is in a valley surrounded by mountain ranges, the air pollutants get accumulated and trapped due to its topography. It has been reported in 2006 that the city of Kandy is heavily polluted and that the level of air pollution has reached dangerous levels, which is even higher than that of Colombo City (4). A study conducted by Siribaddana and colleagues further revealed that there is an increase in the number of patients with cardiovascular disease and respiratory disease affecting both the young and old due to severe air pollution in Kandy City (5). Hospital statistics too have proven this situation with the chronic obstructive pulmonary disease in children rising at an alarming rate (4). However, a more recent study conducted by the Environment Division of the National Building Research Organisation on active and passive monitoring of air for $\mathrm{SO}_{2}$ and $\mathrm{NO}_{2}$, and 24hour monitoring for $\mathrm{PM}_{10}$ in the Kandy Municipal Council (KMC) area, reported that when considering the whole KMC area, about $99 \%$ of the land area was having good air quality, with air quality index (AQI) values being less than 50 (6). A detailed analysis has indicated that more than $92 \%$ of the population in this area is exposed to AQI levels below 40; $8 \%$ exposed to AQI levels between 40-60; and only $0.25 \%$ exposed to AQI values higher than 60 . Though only about $1 \%$ of the area was moderately polluted with AQI more than 50 , this area locates the main bus stand and the railway station, thus greater exposure of the population to air pollution. Large number of daily travellers, high traffic flow and traffic congestion are significant factors that pose negative effects on the quality of air. Kandy is full of magnificent architecture, with countless shrines that display Buddhist and Hindu culture. Attention must be focused to improve the quality of Kandy's air before it affects the health of the city dwellers and tourism, which is an important income generation in the city.

In 2013, when Shanghai disappeared into thick smog, school children were ordered to stay indoors, construction sites were closed-down, and aircrafts were grounded. Lessons learnt from this experience should be translated into environmental protection in countries facing economic transition like in Sri Lanka.

Kandy has been recently chosen as the location for Sri Lanka's first 'Smart City'. With the implementation of this initiative, Kandy City will undergo a major transformation in its infrastructure. 'Sri Dalada Highway' now referred to as the 'Central Expressway' is under construction connecting the two busiest commercial cities in the country. Let us hope that it will not interfere with Kandy's scenic beauty, sanctity and health of people.

\section{References}

1. Kandy - The Hill Capital. Available from: https://www.tourslanka.com/kandy/

2. Sacred City of Kandy. Avaialble from: https://whc.unesco.org/en/list/450

3. Kandy. Available from: https://en.wikipedia.org/wiki/Kandy

4. Abeyratne VDK \& Illeperuma OA. Air pollution monitoring in the city of Kandy: possible transboundary effects. Journal of the National Science Foundation of Sri Lanka 2006; 34 (3): 137-141.

5. Siribaddana A, Wanigasekara PC, Seneviratne K. Aetiology of chronic obstructive pulmonary disease (COPD) in non-smoking women of Kandy district, Sri Lanka. International Scientific Conference, Dubai, UAE, 5-8 December 2010.

Available from: https://wao.confex.com/wao/2010isc/webprogram/Paper2013.html

6. Premasiri HDS, Samarasinghe IHK, Lakmali KMN. Population exposure risk assessment to air pollution in Kandy city area. National Building Research Organization Symposium, Colombo, Sri Lanka, 2012.

Available from: https://www.nbro.gov.lk/images/content_image/publications/symposia/2010/population exposure_risk_assessment.pdf 